\title{
As reformas do ensino público primário como constituintes da política educacional do Estado de Minas Gerais (1891-1906)
}

\author{
Vera Lúcia Nogueira ${ }^{1}$
}

Irlen Antônio Gonçalves ${ }^{2}$

\section{Resumo}

Este artigo apresenta uma análise dos fatores que induziram a produção das reformas educacionais mineiras nas duas décadas iniciais da República, quando se realizaram as principais mudanças no ensino público primário. Como fontes, foram utilizados os Anais do Congresso Mineiro, a legislação educacional, as mensagens e os relatórios dos presidentes. Pode-se afirmar que as reformas assumiram contornos e definições próprios ou desdobramentos ajustados às aptidões étnicas e históricas do Estado, tais como o movimento de difusão, que se deu na direção do litoral para o centro, e a distribuição dos recursos e materialidade das escolas, da cidade para a vila ou distrito. Foram reformas lentas e graduais que buscavam, de forma progressiva, vencer os obstáculos impostos pelas condições hostis do sertão mineiro para levar as luzes da civilização às regiões mais distantes dos grandes centros urbanos.

Palavras-Chave: história da educação; reforma do ensino; política educacional; Minas Gerais; Congresso Mineiro.

1 Doutora em Educação pela UFMG. Professora e coordenadora do Programa de Pós-Graduação em Educação da Faculdade de Educação da Universidade do Estado de Minas Gerais.

vlnogueira@terra.com.br

2 Doutor em Educação pela Universidade Federal de Minas Gerais. Professor do Centro Federal de Educação Tecnólogica de Minas Gerais - CEFET-MG. irlen@terra.com.br 


\title{
The reforms in public education as a constitution of the educational politics in the State of Minas Gerais
}

\begin{abstract}
This article presents an analysis of the factors that led to the production of educational reforms in the state of Minas Gerais, in the first two decades of the republic, when the main changes in primary public education took place. As sources were used the Proceedings from Congress of Minas, the educational legislation, messages and reports of the presidents. It can be said that these reforms were outlined and defined peculiarly and their outcomes adjusted to ethnical and historical aptitudes from the State, such as the diffusion movement, that occurred from the coast to the center, the resources and material distribution to the schools, from the city to the villages or districts. These reforms were slow and gradual that aimed, in a progressive manner, overcome the obstacles imposed by the hostile conditions from the hinterland in Minas to bring the lights of civilization to remote regions, more distant from the great urban centers.
\end{abstract}

Keywords: history of Education; education reform; educational politics; Minas Gerais; Congress of Minas.

\section{Introdução}

Ao final do século XIX, a educação pública emergiu como questão fundamental para a construção do estado republicano, embalado por um ideário democrático que a defendia como fator de progresso, de cidadania e de civilização do povo. Reivindicava-se uma educação capaz de formar o cidadão republicano, incutindo-lhe os novos valores sociais e políticos, seus direitos e deveres, dotando-o de um poder de decisão fundado na razão e no discernimento.

Perpassados pelos ideais democráticos, os discursos dos políticos mineiros defendiam a instrução primária pública como dever do Estado, pois, como dissera o deputado Gomes Freire de Andrade, somente essa 
haveria de "garantir a estabilidade do governo que entre nós se inaugurou e que se baseia no exercício esclarecido e consciente do sufrágio popular" (ANDRADE, 1891, p. 383). Ou ainda, como defendia o senador Joaquim Cândido da Costa Senna, para quem a "instrução [estaria] destinada a fazer do menino um cidadão", abrindo, assim, as portas de seus direitos, deveres e interesses (COSTA SENNA, 1892, p. 188).

Tirar os homens da condição de "menoridade intelectual" era uma palavra de ordem dos políticos que ecoava, frequentemente, no plenário do Congresso Mineiro. Para Costa Senna, nessa condição, o homem não se guiava por si e podia ser considerado "uma verdadeira máquina, que se move pelo impulso que os outros lhe dão [...] sempre obrigado a se deixar levar por conselhos de outros" (COSTA SENNA, 1892, p. 188). Corroborando esse pensamento, o senador Frederico Augusto Álvares da Silva concordava que, sem o discernimento necessário, o homem não poderia "tomar parte no governo do país; isto é: não pode [ria] ser eleitor" (SILVA, 1892, p. 189).

Ao lado da defesa da formação do cidadão republicano, outros discursos, fomentados pelas mudanças processadas nas relações de trabalho no país, em vista da abolição, vinham, também, desde as últimas décadas do Império reclamando da educação o cumprimento de outro papel social, o de regeneradora do povo. Nesse sentido, a educação deveria cumprir, pelo menos, duas atribuições: formar o bom cidadão e o trabalhador, inserindo-o duplamente na sociedade (ARROYO, 1982). Em relação ao trabalhador mineiro, sobressaia a necessidade de uma formação que não somente o dotasse de competência técnica para o desenvolvimento do trabalho, como também promovesse a construção de uma nova relação ressignificada pela positivação dele. Esse era o novo homem de quem os republicanos prescindiam para a consolidação da nova ordem, mas, para isso, era preciso reinventar a escola:

as novas demandas postas pelas mudanças advindas da necessidade de integração do povo à nova ordem republicana e à alocação do trabalhador livre ao mercado de trabalho evidenciaram a necessidade de reinvenção de uma nova escola, como imperativo de atendimento ao projeto de modernização da sociedade. [...] essa perspectiva de reinvenção da escola por meio das políticas educacionais, na década final do século XIX e 
início do século XX evidencia a contribuição que ela poderia dar ao projeto de homogeneização social, pelo menos na intenção de seus construtores (GONÇALVES, 2006, p.37)

A educação poderia ser tomada como um instrumento fundamental para a conservação das condições de subsistência de uma elite "ressentida" pela mudança de regime, ou, então, como instrumento promotor das transformações requeridas para a sedimentação da nova ordem vigente. É em meio a essa tensão que esta análise se encontra: por um lado, entendendo que as políticas públicas podem ser utilizadas como um instrumento importante para a recomposição do poder político, porquanto o lema do momento era reformar a velha ordem, adaptando-a ao novo momento político; e, por outro lado, como um poderoso instrumento de manutenção do status quo dos destinatários das políticas, ou seja, do sujeito trabalhador, principalmente se essas políticas, analisadas em relação aos objetivos propostos, demonstrarem ineficácia.

Onascimento da República coloca em cena várias demandas ocasionadas pela necessidade de produção da nova organização política e social de Minas Gerais, dentre as quais, a educação, cujo objetivo era possibilitar a construção das bases da nova sociedade e, consequentemente, do novo sujeito social, requerido para a consolidação dos ideais dos republicanos mineiros que se encontravam no lugar dos produtores das políticas educacionais do Estado. E é desse lugar que focalizaremos as reformas da instrução pública primária, como uma das medidas do novo Estado para a sua efetivação. Entendendo as reformas da instrução pública primária como expressão da política educacional mineira, esta abordagem se propõe a resgatar os sentidos a elas conferidos, bem como os pressupostos subjacentes à sua implantação e os princípios orientadores dessas medidas, discutidos e implementados ao longo dos anos iniciais da República.

\section{0 ensino primário na pauta de construção do Estado republicano mineiro}

A inserção do ensino público primário na pauta das políticas públicas do Estado de Minas Gerais pode ser situada no final do primeiro quatriênio do governo, tendo como marco dessa inclusão as discussões e a proposição 
do projeto que culminou na primeira reforma republicana, implantada pela Lei n. 41, de 03 de agosto de 1892, dando nova organização à instrução pública do Estado. Durante o Governo Provisório, as demandas mais prementes diziam respeito à própria organização do aparato políticoadministrativo do Estado. Essa organização significou, de acordo com as palavras do presidente Afonso Augusto Moreira Penna, em mensagem dirigida ao Congresso Mineiro, "encaminhar os serviços e adaptar as molas da administração ao novo organismo político. Dessa adaptação, dependeria o retorno à normalidade política no interior das cidades mineiras", após a mudança de regime (MOREIRA PENNA, 1893, p. 5). "Normalidade" vinculada naquele momento à definição e à construção de todo um aparato legal que estruturasse e sustentasse a nova ordem, estabelecida com a Proclamação da República, em $1889^{3}$.

A antiga Província mineira passou a se configurar como um dos mais importantes Estados da Federação, em função da sua forte influência política e de suas atividades econômicas. Aliadas a essas características estavam, ainda, a vastidão de seu território e as múltiplas configurações que cada localidade possuía. Tornara-se, então, imperativo para o novo Estado construir uma nova organização espacial, com base em cartas geográficas e políticas (MOREIRA PENNA, 1893). Era necessário, portanto, conhecer o espaço natural e geográfico, identificar suas forças políticas e principais necessidades e dar-lhe uma nova feição.

Nesse sentido, tornou-se mister a produção de um conjunto de dispositivos que promovesse a reestruturação da vida social e política de Minas, dentre os quais a Lei estadual n. 2, de 14 de setembro de 1891, que determinou os distritos como a nova base de organização administrativa do Estado. A exigência de se promover a instrução pública primária figurava dentre as condições de criação dos distritos, ao lado da delimitação do número mínimo de mil habitantes; da renda líquida municipal anual de um conto de réis; da criação de Conselho Distrital, além de outras.

No âmbito estadual, uma das primeiras iniciativas do Presidente

3 Esse aparato, no âmbito nacional, era composto pela Constituição da República, de 24 de fevereiro; no âmbito estadual, pela Constituição do estado de Minas Gerais, de 15 de junho; no âmbito municipal, pela Lei Mineira de número 2, de 14 de setembro de 1891. 
Afonso Penna foi a regulamentação da lei que criou as três Secretarias: do Interior; da Agricultura, Comércio e Obras Públicas; e a Secretaria das Finanças ${ }^{4}$. A instrução pública constava das atribuições da Secretaria do Estado do Interior, à qual caberia cuidar dos negócios "referentes à justiça, segurança, estatística, saúde pública, magistratura, instrução pública, eleições e leis, bem como das relações do Estado de Minas Gerais com os governos dos outros Estados e com o Governo Federal" 5 . A instrução figurava, portanto, como parte da própria estruturação e construção do novo regime, sendo considerada, inclusive nos municípios, como uma das condições para delimitação geopolítica das regiões.

Após a "reorganização da casa", restava então pensar na reorganização de um dos mais importantes ramos da administração pública, como bem recorda o Secretário de Estado dos Negócios do Interior, Dr. Manoel Thomaz de Carvalho Britto, anos depois: “Já no período constitucional, organizado o nosso Estado com a adoção de seu estatuto político, foi o momento que o legislador mineiro achou próprio para organizar a instrução pública [...] em 1892" (CARVALHO BRITTO, 1908, p. 18). Pode-se então afirmar que o primeiro triênio da República fora totalmente dedicado à organização político-administrativa do Estado e que, a partir de 1891 começou-se a discutir a política educacional republicana.

Assim, 1891 fora um ano de profundas e acaloradas discussões, no Congresso Mineiro, sobre o ensino primário que se tornara objeto efetivo da preocupação da elite política e intelectual de Minas, incorporandose definitivamente à pauta das políticas públicas republicanas. Compreendida como um importante "ramo da administração pública", a instrução primária não poderia ficar fora do processo de construção da ordem republicana, conforme afirmação de Delfim Moreira (RIBEIRO, 1904, p. 14). A exigência de repensá-la se impunha, principalmente, por ela se encontrar impregnada do arcaísmo e dos vícios da velha ordem, trazendo no sistema de ensino vigente as marcas de uma configuração considerada anacrônica, inconcebível para as novas concepções do

4 Trata-se da Lei n. 6, de 16 de outubro de 1891, cuja regulamentação se deu por meio dos Decretos n. 587,588 e 589 .

5 Guia de Fundos e Coleções do Arquivo Público Mineiro. Informações disponíveis em: <www.siaapm. cultura.mg.gov.br/modules/fundos_colecoes/brtacervo.php?cid=35 - 17k>. Acesso em: 03 mar. 2008. 
momento. Era preciso mudar a educação e curar a instrução pública, conforme avaliou o deputado Gomes Freire de Andrade:

no tempo do Império, que foi também o tempo das lições de todo o gênero, tratava-se, é verdade, da instrução, mas de que modo? Programas aparatosos, suntuosos museus, magníficas coleções, um pessoal docente numerosíssimo em nossas faculdades de medicina e de direito e a fama do ex-imperador rebrilhava no estrangeiro, como o príncipe sábio protetor das letras; mas e o povo, este conservava-se nas trevas da mais completa ignorância! (ANDRADE, 1891, p. 384)

Era preciso, nas palavras do deputado Teixeira Costa, empreender uma reforma radical na instrução pública do Estado de forma a "tirála do estado desgraçado em que se achava" (COSTA, 1891, p. 364). A ideia era a de que a primeira reforma inaugurasse "uma nova era para o estado, que precisava deveras da instrução". Era inadmissível cogitar, conforme afirmou o deputado Manoel Teixeira da Costa, "entrar num sistema novo como o atual, em que se dá o direito de voto só a quem sabe ler e escrever, sem que haja a instrução, e esta regular e compatível com as nossas circunstâncias". Para isso, era necessário, pois, que todos se unissem em torno "de um só pensamento e dessa união nascer [ia] uma reforma digna do Estado e que fizesse a sua felicidade" (COSTA, 1891, p. 364-365). Esse empenho foi reconhecido, posteriormente, pelo Secretário do Interior, Manoel Thomaz de Carvalho Britto, ao qual assim se referiu:

Proclamada a República federativa, o governo provisório julgou coisa urgente uma vasta e profunda reforma do ensino em geral, acusado então do maior descrédito possível. Teve, porém, o ministro reformador a idéia de imprimir uma transformação de métodos na direção de nossos estudos, dando-lhes feição inteiramente nova (CARVALHO BRITTO, 1908, p. 18).

Uma renovação que seria possível a partir de uma vasta e profunda reforma que alcançasse a essência do ensino pela transformação de seus métodos. Dos métodos, afirmou o deputado Gomes Freire de Andrade, o mais novo, "de conformidade com a pedagogia moderna", que teria como função primordial a própria transformação do povo mineiro e a sua incorporação à República (ANDRADE, 1891, p. 423). Dessa forma, procede a indagação: como construir um novo homem por meio de um 
modelo de ensino que o prendia à condição de menoridade, enquanto o momento o reclamava como cidadão e como trabalhador? Como consolidar uma nova ordem sem promover, também, uma transformação das instituições públicas?

\section{Os sentidos das reformas da instrução primária pública}

A instrução primária foi cooptada, portanto, como um dos mecanismos de controle social capazes de promover a construção da nova ordem - a ordem republicana -, requerida como essencial à superação da ordem monárquica. Não seria concebível, por conseguinte, mantê-la da mesma forma como estava, urgia convertê-la em uma "nova forma". E não era para o passado que os deputados estavam olhando, como disse o deputado Gomes Freire de Andrade: “[...] se nós já nos demos tão mal com o passado, como havemos de ir buscar nele ensinamentos no passado? Vamos ver se inovando conseguimos alguma coisa em benefício do povo; porque afinal, se assim não procedermos, isto não se poderá chamar república." (ANDRADE, 1891, p. 424).

Reformar e inovar eram as palavras de ordem, "mas devemos fazêlo com critério e prudência, para colhermos das reformas resultados positivos". (RESENDE, 1891, p. 421).

De modo consensual, a política que se assume para a educação, a partir de então, se concretizaria por meio de reformas do ensino. Refletindo com Raymond Williams (2003, p. 278) o sentido conferido ao termo "reforma", pode ser apreendido a partir da sua configuração sóciohistórica e da maneira como esse termo é apropriado pelos discursos das autoridades, durante o período investigado. Inserido nos discursos produzidos e divulgados pelas autoridades responsáveis pelas reformas político-institucionais, o que se pode perceber é que ora esse termo era utilizado para exprimir uma ação, no sentido de promover mudanças, modificações; ou mesmo como sinônimo do produto que esperava resultasse dessa ação, isto é, como melhoramento.

Nesse caso, remeteria ao sentido europeu original que lhe era conferido por volta do século XIV, o de converter a uma "nova forma", vinculado 
à ideia de mudança, preferencialmente, para melhor, como explicitou o deputado Severiano Resende: "tratando da reforma da instrução pública não temos outro passo a dar senão para adiante; não entendendo que se deva reformar para pior ou para conservar o que já possuímos" (REZENDE, 1891, p. 415). Mudança que implicaria construir uma nova configuração para o ensino, para a escola, para o professor, para o inspetor, enfim, para todos os agentes envolvidos com a educação. Era nesse sentido que as reformas republicanas vinham sendo pensadas, como capazes de construir uma educação nova e, por conseguinte, um homem novo.

A reforma implicaria ainda romper com a instituição que carregava a pecha do atraso e do anacronismo, como o que viria a acontecer a partir da implantação da Reforma de 1906; pensada, naquele momento, na convergência com outro sentido: o de "inovação". Assim, restauração e inovação se convergiram em busca do progresso e da modernização da educação, especialmente representada pela criação dos grupos escolares mineiros. As palavras do deputado Severiano de Resende (1891, p. 415) podem bem traduzir, em síntese, o sentido das reformas republicanas, para quem, "reforma quer dizer progresso".

Por outro lado, o termo "reforma" também era utilizado como um substantivo definido, significando "uma medida específica", conforme difundido no contexto europeu, principalmente, a partir do final do século XVIII. Como medida, em Minas Gerais se expressaria por meio de um instrumental jurídico-normativo próprio, destinado a propor e a validar as mudanças, tais como as leis e os regulamentos, como se pode ver nos trechos seguintes: [...] "à lei que autorizou a reforma do ensino" $(1907)^{6} ;[$... " "leia os decretos do governo relativos à reforma do ensino jurídico e ensino médico"(1892)7; “Os católicos mineiros pedem a V. Exa uma lei reformando a instrução primária" $(1912)^{8} ;[$ [... "em virtude da reforma de ensino em elaboração" (1910) ${ }^{9}$. Seja indicando mudanças,

6 CARVALHO BRITTO, Manoel Thomaz de. Relatório apresentado ao Presidente do Estado pelo Secretário do Interior, 1907.

7 CONGRESSO MINEIRO. Anais do Senado. Primeira sessão da primeira legislatura nos de 1891 e 1892. 8 CONGRESSO MINEIRO. Anais da Câmara dos Deputados. Representação do Centro Estadual da União Popular sobre reforma do ensino. Códice: 270. Belo Horizonte: Arquivo Público Mineiro, 1912, p. 440.

9 CONGRESSO MINEIRO - Anais da Câmara dos Deputados. Códice: 270. Belo Horizonte: Arquivo Público Mineiro, 1910, p. 383. 
seja indicando a própria lei, o que se percebe é que havia uma forte crença no poder transformador da educação, pela via do império da lei, principalmente nas primeiras décadas da República quando as reformas foram mais constantes.

Essa concepção de mudança, promovida continuamente pela produção de leis, fazia parte do pensamento político da época e poderia, assim, se justificar, pelas palavras do Secretário do Interior, Delfim Moreira da Costa Ribeiro:

As leis do ensino, na atualidade, não podem ter um caráter fixo e imóvel; devem constituir um organismo sempre vivo, que evolua com as necessidades da sociedade. Os progressos da ciência, os ensinamentos, a experiência didática de outros povos mais adiantados e a nossa própria experiência e observação estão a exigir continuamente novas modificações na escola primária, no aparelho pedagógico e nos métodos e processos de ensino. (RIBEIRO, 1911, p. 30).

Para além desse significado intrínseco, as reformas traduzem mudanças complexas que podem transformar todo um sistema de ensino, configurar uma nação, dar-lhe uma feição moderna, atrasada ou civilizada. Mudanças que, numa perspectiva micro, podem modificar toda a organização de uma escola, suas práticas, seus métodos, enfim, sua cultura. Assim pensadas, as reformas podem ser entendidas como na definição de Viñao Frago (2001, p. 26), designando uma

alteración fundamental de las políticas educativas nacionales que puede afectar al gobierno o administración del sistema educativo y escolar, a su estructura o financiación, al currículum - contenido, metodología, evaluación-, al profesor - formación, selección o evaluación - y a la evaluación del sistema educativo.

Essa definição, que evidencia a amplitude e o alcance das reformas, extrapolando o interior das escolas e implicando a própria organização do estado, nos é bastante pertinente ao corroborar a ideia de que as reformas podem ser entendidas como instrumentos de implementação das políticas educacionais que visam a promover mudanças. As reformas seriam, em síntese, "esfuerzos planificados para cambiar las escuelas con el fin de corregir problemas sociales y educativos percibidos" (TYACK; CUBAN, 1995, p. 4, apud VIÑAO FRAGO, 2001, p. 26). 
No caso das mudanças requeridas para a educação mineira, buscava-se, inicialmente, romper com o passado - da mesma forma que a República rompia com a Monarquia -, e de construir uma nova ordem social, uma nova realidade que expressasse e representasse esse novo momento político. Isso implicava ação. E era isso que o governo mineiro estava fazendo, agindo por meio da criação de uma legislação educacional que se efetivasse a partir de reformas. Nessa direção, estamos compreendendo que a política para a educação mineira foi se delineando nos anos iniciais do século XIX e tomando forma ao longo das primeiras décadas da República, predominantemente, por meio de reformas traduzidas por um instrumental jurídico-normativo específico.

Para a formulação dessas políticas, por meio de medidas específicas - reformas - podem ser observadas algumas "fases": uma primeira que se caracterizaria como sendo o momento de identificação do problema a exigir atenção; noutra seria realizado um levantamento diagnóstico da real situação que envolveria aquele problema; numa terceira, seriam propostas as principais ações para corrigir ou modificar a situação diagnosticada e, por fim, a sua execução. Ao se iniciar um novo ciclo de reformas a primeira "fase" era incorporada à segunda, pois, simultaneamente, eram levantados e identificados os problemas a serem resolvidos.

Essa formulação não estava isenta de conflitos, jogos de interesses e influências diversas, pois, como um assunto público, a educação interessava a variados grupos políticos e sociais. A formulação da política iniciava-se, por conseguinte, a partir de um levantamento diagnóstico da real situação em que se encontrava o ensino público, seguido da discussão e do estabelecimento de uma série de medidas para sanar os problemas detectados e alcançar os objetivos propostos.

Embora os discursos da época anunciassem os princípios basilares da nova política, o encaminhamento dado à educação em Minas não conseguiria cumpri-los: instruir a todos, em todos os lugares; transformar o povo em cidadão e incorporá-lo ao Estado; eram esses os novos propósitos da instrução primária, merecedora da atenção “dos altos poderes do Estado", enquanto responsável pela equalização social. 
Nesse contexto, o ensino primário, conforme defendia o deputado Manoel Tomaz de Carvalho Brito era considerado "o patrimônio que o governo deve a todo cidadão brasileiro", ressurgindo como uma grande promessa, qual seja, a de romper com o quadro de privilégios que obscurecia a vida do povo mineiro (CARVALHO BRITTO, 1908, p. 21). Equalização que significava, assim, o cumprimento do princípio básico da cidadania, base de sustentação da nova ordem, como era constantemente proclamada:

É este, sem dúvida, o assunto mais interessante dos que devam ocupar o administrador, pois a instrução, fartamente derramada é o alicerce único em que pode repousar a verdadeira democracia [...] Um sistema de instrução geral, aplicado a todos os cidadãos, disse Jefferson, "foi o primeiro negócio público por que me interessei e será também o último". Esta voz, diz Carnegie, é a voz inspirada da democracia triunfante que considera seu primeiro dever dar instrução a todos. Ela não tem glória e triunfo de que se possa mostrar mais altiva. Tal a convicção do governo, eminentemente republicano, que iniciou este quatriênio presidencial, ao lançar as bases da reforma da instrução - trazendo este problema para o primeiro plano - tocando sobre ele toda sua atenção (MAGALHÃES PINTO, 1909).

Em vista disso, derramar fartamente a instrução para se cumprir com os ideais democráticos era a tarefa primordial da qual deveriam se ocupar os administradores. $\mathrm{O}$ regime republicano instituiu a necessidade de instrução do povo como condição indispensável para a construção da cidadania e para afirmação da nova ordem social, realçando, de forma definitiva, o papel da educação e a função social e política da escola pública primária. Parecia inconteste, pois, o lugar social ao qual a instrução primária fora alçada, bem assim o parecia o intento de universalizá-la.

\section{A produção das reformas e a legislação educacional mineira}

Considerando que as políticas para a educação mineira se consubstanciaram por meio de reformas do ensino público e que essas foram produzidas no campo jurídico-normativo, valem algumas considerações relativas ao uso da legislação como fonte neste trabalho. 
Compartilhando das observações feitas por Luciano Mendes de Faria Filho (1998) e por Carlos Roberto Jamil Cury (2002), a utilização da legislação como corpus documental pautou-se pelo princípio de que ela não representava todas as vozes dos grupos envolvidos na sua produção, pois se constituía num espaço político legítimo em que se expressavam os mais variados interesses, opiniões e contradições que não seriam apreendidos na lei como produto final. A lei não é um campo isento de lutas e de contradições, ao contrário, ela comporta as lutas e os dissensos, além das vozes silenciadas da e na sociedade (CURY, 2002).

Mas, restringir as fontes apenas à legislação não nos permitiria conhecer essas tensões, disputas, omissões e todo o jogo político envolvido na produção das políticas educacionais, especialmente nos anos iniciais da República quando foram lançadas as principais bases da política educacional republicana. Como diz Saviani (2002, p. 2), “a única maneira eficaz de esclarecer o significado do produto é examinar o modo como foi produzido e, por isso, examiná-lo nos permite compreender o seu significado político". O que significa compreender as políticas educacionais na relação com o contexto político, econômico e social no qual essas foram articuladas pela via jurídico-normativa, contemplando não somente o texto final da lei, como também, e principalmente, os debates, os embates, as divergências e as opções do legislativo e do executivo na produção dessas políticas. Para acessar essas vozes, o Congresso Mineiro se constituiu lugar privilegiado, pois nesse espaço político os parlamentares expressavam as suas opiniões, os seus interesses e concepções sobre os temas em questão, revelando as alianças, as oposições e a importância atribuída ou não a determinada temática.

Toda essa trama tem assento nos Anais do Congresso Mineiro, em que é possível acompanhar os debates dos projetos das primeiras reformas, além de outros projetos fundamentais para uma compreensão do encaminhamento dado à política para a educação mineira. A condução das discussões normalmente acontecia seguindo as normas internas da Casa que previam: primeiro, a apresentação geral do projeto elaborado pela comissão de instrução ou por um deputado ou senador. Em sessão regular era feita a leitura do projeto, acompanhado de uma apresentação 
formal do discurso proponente, para explicitação de toda a proposta e, nesse primeiro momento, não era permitida nenhuma discussão. A partir da apresentação, o projeto era submetido a três discussões ocorridas em sessões plenárias distintas. Quando colocado em segunda discussão, a análise e o debate do projeto se faziam detalhadamente, no geral, artigo por artigo, além da apresentação das emendas. Na terceira discussão, o projeto era submetido à votação plenária. É bom salientar que todos esses procedimentos eram, quase sempre, acompanhados de discursos, ora defendo o projeto, ora refutando-o.

A implementação da política educacional mineira se deu por meio da construção de um ordenamento jurídico-normativo específico que, ao final, traduzia a própria expressão oficial do Estado sobre os rumos da educação. Sabe-se, porém, que uma política não se efetiva apenas com a sanção de uma lei reformista, pois a simples determinação legal não implica a sua eficácia, mesmo porque a escola não é produzida somente por aqueles que detêm o poder de impor, ou de reformar e de controlar tal processo; mas também pelos sujeitos que a produzem cotidianamente com suas práticas, por meio de burlas, negociações etc. (GONÇALVES, 2006). Assim, não se trata, obviamente, de afirmar que todas as proposições prescritivas estabelecidas pelas reformas tenham resultado em eficácia (BOBBIO, 2005), ou seja, que tenham sido cumpridas tal como previstas, pois o que as práticas cotidianas das escolas mostram são diferentes formas de apropriação dos projetos impostos pelo poder estatal (GONÇALVES, 2006).

\section{Pressupostos subjacentes às reformas do ensino primário}

A exequibilidade das reformas do ensino se apresentava como uma preocupação frequente nos discursos dos reformadores mineiros; pode-se até dizer que a Comissão de Orçamento, por vezes, fazia o papel de controladora dos sonhos e desejos mais progressistas. Mas, era preciso ter sempre em mente as condições naturais do Estado e as circunstâncias orçamentárias para se concretizar as medidas propostas, conforme chamou atenção o deputado Manoel Teixeira da Costa durante 
as discussões da primeira reforma, em 1891: “Quero sr. Presidente que a Câmara compenetrando-se da grande responsabilidade que sobre ela pesa faça uma reforma que possa se traduzir em uma realidade em nosso Estado a respeito de instrução primária e não uma reforma impraticável e que ficará somente escrita." (COSTA, 1891, p. 364).

Sua observação se relacionava às ambições da Comissão de Instrução cuja inspiração para a reforma vinha de modelos "estranhos" à realidade do Estado. Sobre essa questão asseverou:

O projeto tem algumas disposições que a receita não comporta. Porquanto ele esteja perfeitamente elaborado, conquanto mostre a ilustração e sabedoria com que foi feito, o muito patriotismo de seus autores, contudo não podemos estabelecer no nosso estado o sistema adotado, por exemplo, nos EUA, na França, Inglaterra, etc. que não têm aplicações para o nosso estado grande como é, com a população completamente disseminada pelo vasto território, o sistema seguido nesses países, porque as nossas finanças não suportam despesas enormes como as que cogitam esse projeto. (COSTA, 1891, p. 365).

A preocupação com os recursos estava vinculada à extensão do Estado e à dispersão da população e, por isso, ainda que o dever da República fosse o de "levar a instrução elementar a todas as camadas da sociedade: ao rico, ao pobre, ao preto e ao branco", como pensava o deputado Olynto de Magalhães (1891, p. 420), era preciso se ater às condições reais e avançar aos poucos, como sugeriu Severiano Resende:

este serviço se fará gradativamente; iremos atendendo a ele todos os anos começando pelos centros mais populosos, pelas cidades mais importantes e, depois, iremos progressivamente acudir às diversas localidades, até chegarmos às mais insignificantes povoações; mas, para isto, é preciso marcharmos com alguma cautela e prudência; porque, do contrário, será legislarmos na areia; a uma lufada de vento desaparecerão todas as bonitas teorias, que figuram no projeto da nobre comissão (Apoiados). (REZENDE, 1891, p. 422).

Preocupações como essas também permearam o pensamento do Secretário do Interior, Delfim Moreira da Costa Ribeiro, em 1904. Em relatório enviado ao Presidente do Estado, retomava algumas observações feitas anteriormente e aproveitava para lembrá-lo dos cuidados que deveriam ter para que a próxima reforma fosse fecunda e 
não onerasse tanto aos cofres públicos: “[...] tivemos ocasião de lembrar, no relatório anterior, a necessidade de operar uma reforma gradual do ensino público do Estado, no dúplice intento de torná-lo mais fecundo e de se compensar melhor o pesado sacrifício que ao tesouro acarreta este complexo serviço". (RIBEIRO, 1904, p. 14).

Reforçando ainda mais esse argumento, prosseguiu:

Agora, insistindo na mesma ordem de ideias, pedimos vênia para dizer que, apesar de não serem ainda tão lisonjeiras as condições das "finanças mineiras", então atingidas pelas conseqüências de uma crise econômica generalizada, é o caso de se tentar e realizar uma reforma parcelada do ensino público, visto a reconhecida ineficácia do regime atual (RIBEIRO, 1904, p. 15).

Com uma explícita crítica ao transplante incondicional de ideias para Minas, asseverou que a reforma, "gradual" e "parcelada", também não deveria ser cópia do que se praticava nos países civilizados, pois era preciso considerar as especificidades do Estado:

Certo não é lícito se pretenda, com proveito, implantar entre nós reforma radical do ensino público mediante cópia incondicional do que se há feito nos países de civilização realizada, tanto mais quanto se trata de uma questão que deve, por força, estar ligada à questão geral de nossa organização política e às nossas condições sociais. Deve ser, sem dúvida, um desdobramento contínuo e normal de nossas aptidões étnicas e históricas (RIBEIRO, 1904, p. 15).

Esses argumentos, além de reforçar as suas críticas em relação à transposição de ideias alheias às condições mesológicas e econômicas do Estado, também deixavam claro que os efeitos das reformas não seriam alcançados senão em longo prazo. As reformas que ele defendia deveriam levar em conta as "condições sociais e políticas" de Minas, não podendo ser, então "radicais", pois estariam desconsiderando, enfim, as "condições mesológicas" do Estado: "[...] o legislador mineiro, portanto, prudente como tem sido, não pode ter neste assunto movimentos bruscos de organização e desorganização, nem ir buscar no estrangeiro instituições que lhe são peculiares e que as nossas condições mesológicas não comportam". (RIBEIRO, 1904, p. 15).

Ao considerar as condições mesológicas, políticas e sociais, a direção das reformas estaria determinada: "o escasso povoamento deste imenso 
país, o que é óbvio, veio em marcha do litoral para o centro, e com ele a civilização também". (RIBEIRO, 1904, p. 20) Era esse o sentido da difusão do ensino primário, não só em Minas como também no restante do país, conforme avaliou Delfim Moreira:

O ensino primário obedeceu ao mesmo movimento, de modo que é patente a força diferencial que se nota entre o que existe no litoral e no interior do país, onde há extensas regiões onde é ele virtualmente desconhecido. Este fato, especializando-se, bem pode ser observado dentro dos nossos limites territoriais, cujas zonas apresentam cultura intelectual diversa e maior ou menor grau de civilização na massa popular. (RIBEIRO, 1904, p. 20)

Reafirmando a necessidade de uma instrução diferenciada e adequada a cada localidade, assim se expressou: "Pelo exposto, parece que a instrução primária devia variar, não de zona em zona, o que seria odioso, mas de localidade a localidade, conforme a sua classificação de cidade, vila ou distrito, apesar de semelhante classificação não ser, às vezes, rigorosamente justa." (RIBEIRO, 1904, p. 20).

Essa reconhecida desigualdade também já constava dos critérios de elaboração da reforma de 1892, como explicou o deputado Bernardino de Lima sobre a distribuição das cadeiras pelo Estado:

Essa distribuição, pois, das cadeiras, das escolas primárias [...] corresponde perfeitamente à desigualdade do desenvolvimento dos habitantes do Estado de Minas. Nós sabemos que pela diversidade dos elementos naturais, pela grande extensão do território e por outras circunstâncias, a civilização, o grande adiantamento, o desenvolvimento material e moral, em uma palavra, dos diversos habitantes de Minas é muito diferente e desigual em diversos pontos do território. (LIMA, 1891, p. 412).

Anos depois, o Secretário Delfim Moreira ainda reafirmaria os princípios que deveriam ser levados em conta na proposição das reformas do ensino mineiro; insistia na imprudência que seria realizar uma reforma "radical" e apontava alguns dos principais problemas que impediam o progresso das reformas e que precisavam ser enfrentados para o êxito das políticas educacionais de Minas:

Bem sei que, para os radicais e os que querem ver tudo realizado de um fôlego, sem contar com os embaraços da 
ocasião, não pode satisfazer esse desenvolvimento lento, mas progressivo, do ensino público, cumprindo-me acrescentar, com relação ao problema, que a sua máxima desenvolução está intimamente ligada à solução de outros problemas nacionais - o povoamento do solo e o desenvolvimento da viação geral. Realizados estes, o ensino público progredirá forçosamente, porque estarão suprimidas as distâncias, a inacessibilidade dos lugares, que muito dificultam a instalação conveniente das escolas, a fiscalização e a execução da lei da obrigatoriedade do aprendizado primário. (RIBEIRO, 1906, p. 13).

Para adentrar os sertões de Minas e levar as luzes da civilização, Delfim Moreira reconhecia, inclusive, que seria necessário um estímulo extra aos professores efetivos que aceitassem a missão de levar ao interior "o evangelho do ensino e da educação": "Esses que se prepuseram a penetrar os quarteirões pobres dos sertões, serão verdadeiros agentes filantrópicos, formarão uma das classes mais importantes e úteis de uma sociedade e prestarão uma tal soma de serviços que dificilmente se encontrará paralelo nos prestados por outras classes." (RIBEIRO, 1906, p. 13).

Reforçando ainda mais as dificuldades decorrentes das condições mesológicas de Minas, bem como a necessidade de se implantar as reformas de maneira gradual, a opção pela normalista, instituída pela Reforma de 1906, foi colocada em questão, visto ter-se o entendimento de que os atributos femininos não seriam compatíveis à tarefa de desbravamento dos sertões, como ressaltou o Secretário:

A orientação nova é para confiar-se o ensino primário à mulher; essa substituição, porém, só se poderá fazer, em nosso Estado, gradativa e lentamente. Dadas às condições atuais da inacessibilidade dos lugares e da rudeza do meio, a professora normalista não poderá, como o professor, afrontar os sertões; procurará naturalmente localizar-se na orla mais civilizada. O sertão mineiro é a resistência habitual do analfabetismo o mais grosseiro e indisciplinado e a professora não tem as condições de energia e resistência morais para desbravá-lo. (RIBEIRO, 1911, p. 28).

Dessa maneira, a própria opção pela normalista estaria, também, condicionada às condições de acessibilidade aos sertões mineiros, o que requereria energia e resistência moral, atributos que a ela faltavam. 


\section{Princípios orientadores das reformas de ensino mineiras}

Da avaliação do Secretário Delfim Moreira podem ser extraídos alguns dos critérios ou princípios que foram incorporados à elaboração e execução das reformas de ensino em Minas Gerais. Sobre o primeiro: atenção às condições mesológicas. Minas Gerais é o quarto Estado em extensão territorial e, naquele momento, as condições naturais do território eram as mais adversas, com regiões densamente povoadas enquanto outras, referidas como os sertões, apresentavam grande dispersão populacional. Situação que se agravava pela precariedade do sistema de transporte e de comunicação que, no tocante às reformas, dificultava a ampliação do número de escolas, o provimento das cadeiras mais distantes dos centros populosos; a distribuição de materiais didáticos; a inspeção do ensino e a consequente fiscalização do cumprimento da obrigatoriedade escolar; enfim, dificultava democratizar a escola e levar a missão civilizatória em direção ao interior do Estado. Exemplo dessa implicação pode ser confirmado nos termos do Edital de 18 de maio de 1911, que estabelecia as normas para a distribuição de materiais às escolas isoladas e grupos escolares do Estado:

às escolas isoladas sitas em localidades distantes de estrada de ferro, a Secretaria pode fornecer somente os livros de escrituração e didáticos, mapas geográficos e impressos acima mencionados, porque são os únicos objetos que a administração dos Correios aceita para expedir em suas malas. Se, porém, a localidade onde exista escola for servida de estrada de ferro, poder-se-á fazer remessa do mesmo que se manda para os grupos (regra $1^{\mathrm{a}}$, última parte), uma vez que sobre o professor e sua escola haja boas referências nesta Secretaria (JORNAL MINAS GERAES, 1911, p.7).

O provimento material das escolas isoladas, localizadas nas regiões mais distantes do Estado, era restringido e condicionado à capacidade de expedição dos correios e, também, à proximidade das linhas férreas.

Outro princípio a ser considerado na proposição das reformas, mas, sem o qual essas seriam inviáveis, estava ligado aos aspectos orçamentários, como bem explicitou o deputado Severiano de Resende: "é preciso fazerse a luz, mas para que ela irrompa é preciso, pelo menos, kerosene ou eletricidade, e isto custa dinheiro" (1891, p.416). 
A opção dos reformadores era, portanto, a de investir nas escolas localizadas nos principais centros urbanos, em vista dos gastos excessivos que seriam necessários para enfrentar as condições mesológicas do Estado. Nesse sentido, uma condição somava-se a outra e se constituíam impedimentos para a realização do intento de civilizar, de instruir o povo mineiro. Dessa forma, as reformas deveriam respeitar e seguir as características naturais do estado quanto à extensão territorial e à distribuição populacional. Essas condições acabavam restringindo a abrangência das políticas educacionais em Minas, como se pode ver no relatório que o inspetor Estevam de Oliveira apresentou ao Secretário do Interior do Estado, em 1902:

Com uma população rarefeita, disseminada pelo seu vastíssimo território, na proporção aproximadamente de seis habitantes por km quadrado, o Estado de Minas só pode agora encarar o problema do ensino elementar nos seus contornos gerais, a fim de coordenar daí quanto seja, na atualidade, praticamente adaptável a núcleos de população condensada. Caberá depois ao tempo generalizar os efeitos da reforma (OLIVEIRA, 1902, p. 6)

Ao tempo também caberia mostrar os resultados das reformas. Assim, quase uma década depois, o Secretário Delfim Moreira reconhecia que os ideais democráticos ainda não haviam sido consolidados. Dessa forma, a proclamada universalização, o derramamento das luzes a todos, a formação do cidadão e do trabalhador pareciam ainda não concretizados, como se pode ver no relatório do Secretário do Interior, apresentado ao Presidente do Estado Júlio Bueno Brandão, em 1911:

Apesar de estarmos ainda a uma grande distância, não só do que prescrevem os novos princípios relativos ao assunto, mas também do que já é uma realidade no seio de outros povos de civilização realizada, forçoso é confessar a V. Ex. que o nosso Estado está seriamente empenhado em incrementar e difundir o ensino primário, que os poderes públicos não têm poupado toda a sorte de sacrifícios para levar esse ensino a todas as camadas da sociedade e que ele se dilata e se distende presentemente por todas as zonas do Estado; numas, de um modo mais vigoroso e intenso, pela presteza das comunicações e conseqüente facilidade da fiscalização; noutras, com alguma lentidão, pelos obstáculos naturais que se antepõem à ação administrativa (RIBEIRO, 1911, p. 26). 
Mesmo reconhecendo o esforço dos republicanos que os precederam na tentativa de consecução do ideal republicano, para Delfim Moreira, o Estado mineiro ainda teria que investir muito para "fazer do povo mineiro um povo culto, organizado e disciplinado pela cultura intelectual e pela educação cívica" (RIBEIRO, 1911, p. 26).

Além dos pressupostos aqui explicitados para elaboração e execução das reformas mineiras nas décadas iniciais da República, outro princípio básico esteve subjacente à formulação das políticas educacionais em Minas Gerais, ao longo da Primeira República: a opção pela educação da criança. A centralidade na criança, como sujeito da educação, já insinuada nos discursos das elites que propugnavam uma formação para o trabalho que começasse na infância, torna-se indiscutível e se expressa ao longo de, praticamente, toda a legislação educacional, nos discursos dos políticos e intelectuais, nos relatórios dos inspetores, nos programas de ensino etc.

Não é novidade o fato de que a escola moderna teve na criança a centralidade de todo o processo educativo, seja na construção e prescrição de métodos pedagógicos, na obrigatoriedade escolar ou ainda na produção de um espaço e tempo escolares específicos. A escolarização da infância, como destaca Veiga (2005) pode também ser identificada nas reformas escolares de finais do século XIX em todo o ocidente, a partir das próprias "operações escriturísticas" da administração pública. Como destaca, "a escolarização da infância a partir do século XIX foi o objetivo central dos procedimentos relativos à normatização da instrução pública elementar" (p. 77). O esforço para tornar a infância escolarizada pode, assim, ser apreendido no conjunto da legislação da instrução pública, pois é nesse corpus que estão as prescrições que tencionaram produzir as condições específicas para que tal esforço se concretizasse.

\section{Considerações}

Como vimos, a instrução era um dos principais ramos da administração pública do qual se ocuparam os legisladores responsáveis pela produção da República, em Minas. A instrução pública primária, como um dos principais instrumentos de construção da ordem republicana, ocupou 
a pauta dos debates relativos às reformas do ensino, no Congresso, evidenciando uma preocupação que perpassou os vários mandados dos governantes mineiros que viam na reinvenção da escola a possibilidade de renovação da sociedade e dos cidadãos. Para viabilizar as mudanças almejadas era preciso eliminar os resquícios da educação arcaica, a começar pelos métodos de ensino, considerados o cerne de toda a educação e responsáveis pela construção do novo cidadão republicano.

Nesse processo de mudanças, não havia dúvidas quanto ao lugar ocupado pelas reformas da instrução: reformar era converter a uma nova forma, por meio de medidas jurídico-normativas específicas, tais como: a Lei n. 41 de 1892, Lei n. 281 de 1899 e a Lei n. 439 de 1906, responsáveis pelas principais reformas da instrução pública primária nos anos iniciais da República.

Mas, para a efetivação das reformas não bastava apenas a defesa apaixonada ou o empenho dos legisladores ou, ainda, o desejo dos presidentes do Estado; era preciso enfrentar as condições reais nas quais a instrução primária do povo se concretizaria. Condições intrínsecas a um dos maiores estados da federação, em termos de extensão territorial e com grande dispersão populacional. Não era possível, simplesmente, transladar os maiores feitos das reformas realizadas na Europa ou nos Estados Unidos, sendo que as condições políticas, sociais e mesológicas do Estado não lhes permitiam aqui serem reproduzidas.

As reformas do ensino, em Minas Gerais, foram assumindo contornos e definições próprios ou desdobramentos ajustados às nossas aptidões históricas. Desde o movimento de difusão, na direção do "litoral para o centro", como no restante de todo o país, da distribuição desigual, da cidade para a vila ou distrito, o que se fazia era uma reforma lenta e gradual que buscava, de forma progressiva, vencer os obstáculos impostos pelas condições hostis do sertão mineiro e levar as luzes da civilização às regiões mais distantes dos grandes centros urbanos. Para isso, era preciso contar, também, com as devidas condições orçamentárias, afinal derramar as luzes a todos, fazer do povo mineiro, a partir da infância, um povo culto, organizado e disciplinado, "custava dinheiro". 


\section{Referências}

ANDRADE, G. F. de, (Barão de Itabira). Anais da Câmara dos Deputados. Congresso Mineiro. Belo Horizonte: Imprensa Oficial; Arquivo Público Mineiro, 1891.

ARROYO, M. G. The making of the worker: education in Minas Gerais, Brazil (1888-1920). 1982. 265 f. Dissertation (Doctor of Philosophy), Stanford University, 1982.

BOBBIO, N. Teoria da Norma Jurídica. 3. ed. Bauru, SP: EDIPRO, 2005.

CARVALHO BRITTO. M. T. de. Secretaria do Interior. Relatórios apresentados ao Exmo. Sr. Dr. João Pinheiro da Silva, Presidente do Estado de Minas Gerais pelo Dr. Manoel Thomaz de Carvalho Britto, Secretário de Estado dos Negócios do Interior. Belo Horizonte: Arquivo Público Mineiro, 1907-1908.

COSTA SENNA, J. C. da. Annaes do Senado. Primeira Sessão da Primeira Legislatura nos anos de 1891 e 1892 e Sessão Extraordinária Convocada para o dia 10 de março de 1892. Congresso Mineiro. Cidade de Minas: Imprensa Oficial; Arquivo Público Mineiro, 1892.

COSTA, M. T. da. Anais da Câmara dos Deputados. Congresso Mineiro. Belo Horizonte: Imprensa Oficial; Arquivo Público Mineiro, 1891.

CURY, C. R. J. Legislação educacional brasileira. Rio de Janeiro: DP\&A, 2002.

FARIA FILHO, L. M. A legislação como fonte para a história da educação: uma tentativa de interpretação. In: FARIA FILHO, Luciano Mendes (org). Educação, modernidade e civilização: fontes e perspectivas de análise para a história da educação oitocentos. Belo Horizonte: Editora Autêntica, 1998. p. 90-125.

GONÇALVES, I. A. “Cultura escolar": práticas e produção dos grupos 
escolares em Minas Gerais (1891/1918). Belo Horizonte: Autêntica, 2006.

JORNAL MINAS GERAES. Editais. Distribuição de materiais às escolas isoladas e grupos escolares do Estado. Belo Horizonte: Imprensa Oficial, 18 mai. 1911.

LIMA, B. Anais da Câmara dos Deputados. Congresso Mineiro. Belo Horizonte: Arquivo Público Mineiro, 1891.

MAGALHÃES PINTO, E. L. de. Secretaria Do Interior. Relatórios apresentados ao Exmo. Sr. Dr. Wenceslau Braz Pereira Gomes, presidente do Estado de Minas Gerais, Secretário de Estado dos Negócios do Interior em 1909-1910. Belo Horizonte: Arquivo Público Mineiro, 1909-1910.

MAGALHÃES, O. de. Anais da Câmara dos Deputados. Congresso Mineiro. Belo Horizonte: Imprensa Oficial; Arquivo Público Mineiro, 1891.

MINAS GERAIS. Lei n. 281, de 16 de setembro de 1899. Dá nova organização à instrução pública do Estado de Minas Gerais. Minas Gerais, Belo Horizonte, 16 set. 1899.

MINAS GERAIS. Lei n. 41, de 03 de agosto de 1892. Dá nova organização à instrução pública do Estado de Minas. Minas Gerais. Ouro Preto, 03 ago. 1893.

MINAS GERAIS. Lei n. 439 de 28 de setembro de 1906. Autoriza o governo a reformar o ensino primário, normal e superior do Estado e dá outras providências. Minas Gerais. Belo Horizonte, 28 set. 1906.

MOREIRA PENNA, A. A. Mensagem dirigida ao presidente do Estado de Minas Gerais em sua terceira sessão ordinária da $1^{a}$ legislatura. Congresso Mineiro. Ouro Preto: Imprensa do Estado de Minas Geraes, 1893. Disponível em: <http://brazil.crl.edu/bsd/bsd/489/index.html>. Acesso em: 02 jan. 2010.

OLIVEIRA, E. J. C. de. Reforma de ensino público primário e normal em 
Minas Gerais. Belo Horizonte: Imprensa Oficial do Estado de Minas Gerais, 1902.

REZENDE, S. de. Anais da Câmara dos Deputados. Congresso Mineiro. Belo Horizonte: Imprensa Oficial; Arquivo Público Mineiro, 1891.

RIBEIRO, D. M. da C. Secretaria do Interior. Rascunhos de ofícios n. 10. $7^{\mathrm{a}}$ secção. Setembro a dezembro de 1911. Códice: SI 3819. Belo Horizonte: Arquivo Público Mineiro, 1911.

RIBEIRO, D. M. da C. Secretaria do Interior. Relatório apresentado ao Dr. Presidente de Estado de Minas pelo Secretário de Estado dos Negócios do Interior dr. Delfim Moreira da Costa Ribeiro em o ano de 1906. Belo Horizonte: Arquivo Público Mineiro, 1906.

RIBEIRO, D. M. da C. Secretaria do Interior. Relatório apresentado ao sr. dr. Presidente do Estado de Minas Gerais pelo Secretário de Estado de Negócios do Interior, dr. Delfim Moreira da Costa Ribeiro. Volume 1. Filme 070, G-6, Obra Rara. Belo Horizonte: Arquivo Público Mineiro, 1904.

SILVA, F. A. Á. da. Anais da Câmara dos Deputados. Congresso Mineiro. Belo Horizonte: Imprensa Oficial; Arquivo Público Mineiro, 1892.

VEIGA, C. G. Produção da infância nas operações escriturísticas da administração da instrução elementar no século XIX. Revista Brasileira de História da Educação, São Paulo, n. 9, p. 73-108, jan./jun. 2005.

VIÑAO FRAGO, A. ¿Fracasan las reformas educativas? La respuesta de un historiador. In: SOCIEDADE BRASILEIRA DE HISTÓRIA DA EDUCAÇÃO. Educação no Brasil: história e historiografia. Campinas: Autores Associados: São Paulo: SBHE, 2001.

Recebido em 27/02/2014 Aprovado em 05/05/2015 